\title{
Dry reforming of methane by combined spark discharge with a ferroelectric
}

\author{
Wei-Chieh Chung, Moo-Been Chang* \\ Graduate Institute of Environmental Engineering, National Central University, \\ No.300, Zhongda Road, Zhongli District, Taoyuan City 32001, Taiwan
}

*Corresponding author

Address: No.300, Zhongda Road, Zhongli District, Taoyuan City 32001, Taiwan E-mail: mbchang@ncuen.ncu.edu.tw

Phone: +886-3-4227151-34663

Fax: +886-3-4226774 


\title{
Dry reforming of methane by combined spark discharge with a ferroelectric
}

\author{
Wei-Chieh Chung, Moo-Been Chang* \\ Graduate Institute of Environmental Engineering, National Central University, \\ No.300, Zhongda Road, Zhongli District, Taoyuan City 32001, Taiwan
}

\begin{abstract}
The increasing anthropogenic emission of greenhouse gases (GHGs) is causing global warming which is a matter of deep public concern. Dry reforming of methane (DRM) is an attractive means of reducing the emission of GHGs, because it can convert $\mathrm{CO}_{2}$ and $\mathrm{CH}_{4}$ into syngas. Non-thermal plasma has been investigated for use in DRM and the results demonstrate that plasma can convert $\mathrm{CO}_{2}$ and $\mathrm{CH}_{4}$ into syngas at a lower temperature than catalysis, but the specific energy is relatively high. Combining a catalyst with non-thermal plasma in hybrid system can produce various synergistic effects that reduce specific energy. In this work, $\mathrm{BaZr}_{0.05} \mathrm{Ti}_{0.95} \mathrm{O}_{3}(\mathrm{BZT})$ with a perovskite structure and ferroelectric property is packed into the plasma reactor to form a hybrid system. The syngas generation efficiency of BZT with a spark discharge reactor is investigated. The spark discharge reactor yields $49.4 \%$ conversion of $\mathrm{CO}_{2}$ and $79.0 \%$ conversion of $\mathrm{CH}_{4}$ and the $\mathrm{BZT}$ packed bed reactor yields $79.0 \%$ conversion of $\mathrm{CO}_{2}$ and $84.2 \%$ conversion of $\mathrm{CH}_{4}$. With respect to energy utilization, the BZT packed bed reactor has an specific energy of $0.218 \mathrm{MJ} / \mathrm{mol}$, which is $18.7 \%$ lower than that of the spark discharge reactor without a ferroelectric $(0.268 \mathrm{MJ} / \mathrm{mol})$. Characterization of BZT reveals that the presence of BZT increases the charge density in the plasma reactor, favoring $\mathrm{CO}_{2}$ and $\mathrm{CH}_{4}$ dissociation. Also, SEM and XPS results
\end{abstract}


show that BZT is modified with plasma, resulting in a positive synergy between the plasma and the ferroelectric.

Keywords: CCUS, dry reforming of methane, syngas, plasma catalysis, ferroelectric

\section{Introduction}

Global warming has been a public concern since the late $20^{\text {th }}$ century and various techniques for reducing anthropogenic emission of greenhouse gases (GHGs) have been developed [1]. Among them, carbon capture, utilization and storage (CCUS) may be effective. Carbon utilization is a set of techniques that convert $\mathrm{CO}_{2}$ into useful chemicals, including urea, salicyclic acid and syngas [2]-[4]. Reforming $\mathrm{CH}_{4}$ with $\mathrm{CO}_{2}$, which is called the dry reforming of methane (DRM, Reaction 1), is a technique that can potentially reduce $\mathrm{CH}_{4}$ and $\mathrm{CO}_{2}$ emissions simultaneously because it converts $\mathrm{CH}_{4}$ and $\mathrm{CO}_{2}$ into syngas $\left(\mathrm{H}_{2}+\mathrm{CO}\right)$ which can be a feedstock for the Fischer-Tropsch process for synthesizing straight-chain hydrocarbons (Reaction 2) [5]-[8]. Additionally, syngas is a good fuel which can be combusted to generate electricity [9].

$$
\begin{array}{ll}
\mathrm{CH}_{4}+\mathrm{CO}_{2} \leftrightarrow 2 \mathrm{H}_{2}+2 \mathrm{CO} & \Delta \mathrm{H}_{298 \mathrm{~K}}^{\circ}=247 \mathrm{kj} / \mathrm{mol} \\
(2 n+1) \mathrm{H}_{2}+n \mathrm{CO} \rightarrow \mathrm{C}_{n} \mathrm{H}_{(2 n+2)}+n \mathrm{H}_{2} \mathrm{O} &
\end{array}
$$

Dry reforming techniques, including catalysis and plasma reforming, have been investigated for converting GHGs and generating syngas. In catalytic reforming, noble metals and Ni-based catalysts are commonly used. Noble metal catalysts exhibit good activity and durability, but their high cost limits their range of application [10]-[13]. Ni-based catalysts have comparable activity and lower cost, but their shorter lifetime compared to noble metal catalysts, caused by coke deposition, inhibits 
their commercialization [14]-[18].

Plasma reforming is another technique that has been extensively studied. Various plasma reactors including corona discharge, dielectric barrier discharge, arc discharge, atmospheric-pressure glow discharge, spark discharge, microwave and thermal plasma have been investigated for DRM to generate syngas [19]-[25]. Thermal plasmas have a larger treating capacity and a higher energy consumption than non-thermal plasmas. Non-thermal plasmas have a lower energy consumption, but they generate less syngas, which is a major disadvantage. Therefore, increasing syngas generation efficiency using non-thermal plasma is a critical challenge.

Combining plasma with a catalyst to form a hybrid plasma-catalysis reactor has the potential to enhance DRM performance. Currently, the two ways to combine plasma and catalyst are: to place a catalyst process after the plasma process, as in post-plasma catalysis (PPC) and the other is to place the catalyst inside the plasma reactor, as in in-plasma catalysis (IPC) [26]-[27]. In PPC, the catalyst may strongly react with the intermediate species that are generated by the plasma, enhancing catalytic performance [28]. In IPC, the synergistic effects of plasma and catalyst are complex and DRM efficiency is expected to be improved [29]-[32]. Many catalysts have been used in hybrid systems including PPC and IPC and possible synergistic effects have been identified. However, such hybrid system for DRM faces several challenges, such as insufficient operating time, limited lifetime of the catalyst and low energy utilization [7],[31].

A ferroelectric has the unique characteristic of spontaneous electric polarization. It can be polarized by applying an external electric field, so it has a higher dielectric constant than an insulator. The polarization of a ferroelectric remains at a certain strength when the external electric field is removed, and this feature can be exploited in many electric products, such as random access memory (RAM) and 
radio-frequency identification (RFID). The polarization of a ferroelectric generates surface charge which can interact with free electrons in plasma, increasing the energy density in the plasma reactor [33]-[34]. Previous studies have demonstrated that syngas generation efficiency can be enhanced by introducing a ferroelectric into plasma reactor [7],[35]. In this work, ferroelectric powder $\left(\mathrm{BaZr}_{0.05} \mathrm{Ti}_{0.95} \mathrm{O}_{3}\right)$ that is prepared by the sol-gel method and utilized in a spark discharge reactor to determine the DRM efficiency. The characteristics of the ferroelectric are discussed and possible synergistic effects between ferroelectric and plasma are suggested.

\section{Experimental section}

A. Preparation of ferroelectrics

A ferroelectric is prepared by the sol-gel method as followings [36]. 0.04 mole of barium nitrate $\left(\mathrm{Ba}\left(\mathrm{NO}_{3}\right)_{2}\right)$ and 0.04 mole of citric acid were dissolved in $40 \mathrm{~mL}$ of deionized water, and 0.002 mole of zirconium ethoxide $\left(\mathrm{Zr}\left(\mathrm{C}_{3} \mathrm{H}_{7} \mathrm{O}\right)_{4}\right)$ and 0.038 mole of titanium butoxide $\left(\mathrm{Ti}\left(\mathrm{C}_{4} \mathrm{H}_{9} \mathrm{O}\right)_{4}\right)$ were dissolved in $40 \mathrm{~mL}$ of $\mathrm{n}$-propanol. The two solutions were mixed and stirred for 1 hour at $80^{\circ} \mathrm{C}$. Next, 0.04 mole of ethyl glycol was dissolved in $40 \mathrm{~mL}$ of deionized water and the solution was added to the above mixture with stirring for 4 hours at $90^{\circ} \mathrm{C}$. Then, the mixture was stirred at $85^{\circ} \mathrm{C}$ until the gel was formed. The gel-like mixture was dried overnight at $120^{\circ} \mathrm{C}$ and then calcined at $1,150^{\circ} \mathrm{C}$ for 2 hours at a ramping rate of $5^{\circ} \mathrm{C} / \mathrm{min}$ to obtain nanocrystalline $\mathrm{BaZr}_{0.05} \mathrm{Ti}_{0.95} \mathrm{O}_{3}$. The powder was then crushed and sieved into two groups of pellets of different sizes: one was 40-70 mesh and the other was 120-140 mesh, corresponding to sizes of $210-420$ and $105-125 \mu \mathrm{m}$, respectively. The pellets were calcined again using the same procedure as above to stabilize the crystals. The forms of BZT are denoted as C-BZT (coarse BZT particles of size of 210-420 $\mu \mathrm{m}$ ) and 
F-BZT (fine BZT particles of size of 105-125 $\mu \mathrm{m}$ ), respectively. To elucidate the influence of plasma on BZT, the C-BZT powder after plasma catalysis test was further characterized as and is designated C-BZT-P (coarse BZT particles used for plasma catalysis) for the comparison with unused C-BZT powder.

\section{B. Characterization of ferroelectrics}

C-BZT and C-BZT-P were characterized by X-ray diffraction (XRD). The XRD patterns were obtained with a D8AXRD diffractometer using $\mathrm{Cu}$ Kamonochromatic X-rays and operated at $40 \mathrm{kV}$ and $40 \mathrm{~mA}$ over scattering angles $2 \theta$ from $20^{\circ}$ to $100^{\circ}$ in steps of $0.05 \%$ s. The nitrogen adsorption and desorption isotherms of the ferroelectric were obtained at $77 \mathrm{~K}$ using a Micromeritics ASAP-2010 Analyzer while the specific surface areas and average pore diameters were calculated by the Brunauer-Emmett-Teller (BET) method and the Barrett-Joyner-Halenda (BJH) method using the nitrogen adsorption/desorption data within the $0.05-1 \mathrm{P} / \mathrm{P}_{0}$ range. X-ray photoelectron spectroscopy (XPS, Thermo VG-Scientific Sigma Probe) was used to analyze the oxidation state and chemical bonding of C-BZT and C-BZT-P powder. Finally, the morphologies of the ferroelectric were studied by scanning electron microscopy (SEM, FEI Nova NanoSEM 230), and an INCA X-sight energy dispersive X-ray microanalysis (EDS) system was then used to verify semi-quantitatively the composition of the supported phases.

\section{Experimental setup}

Figure 1 presents the experimental setup. The spark discharge reactor comprises one glass tube, one stainless steel tube and one stainless steel rod. The glass tube has an outer diameter of $24 \mathrm{~mm}$ and a length of $360 \mathrm{~mm}$. One stainless steel tube with an 
outer diameter of $6 \mathrm{~mm}$ and an inner diameter of $3 \mathrm{~mm}$ is connected to a DC pulse power supply as the cathode. Another solid stainless steel with an outer diameter of 8 $\mathrm{mm}$ is connected to ground and serves as the ground electrode. The DC pulse power supply provides DC pulse voltages of up to $20 \mathrm{kV}$ and a discharge frequency of up to $20,000 \mathrm{~Hz}$. In this work, the discharge frequency is fixed at $20,000 \mathrm{~Hz}$. The feeding rates of gaseous reactants including $\mathrm{CH}_{4}(99.99 \%)$ and $\mathrm{CO}_{2}(99.99 \%)$ are controlled by mass flow controllers in the range of 10 to $100 \mathrm{~mL} / \mathrm{min}$. The influent gas is fed into the stainless steel tube, and the discharge is induced in the gap between two electrodes, which is fixed at $5 \mathrm{~mm}$. Thus, the total discharge volume is $0.14 \mathrm{~mL}$ with the gas hourly space velocity (GHSV) being in a range of 8,500 and 85,000 $\mathrm{hr}^{-1}$. The effluent gas was analyzed using a gas chromatography (HP6980N) that was equipped with a thermal conductivity detector (TCD) and a flame ionization detector (FID). Two columns, an HP/PLOT-Q (capillary: $30.0 \mathrm{~m}$ x $530 \mu \mathrm{m}$ x $40 \mu \mathrm{m}$ nominal) and an HP/Molesieve 5A (capillary: $30.0 \mathrm{~m} \times 530 \mu \mathrm{m} \times 25 \mu \mathrm{m}$ nominal), were used to separate gas components. $\mathrm{N}_{2}(99.99 \%)$ with a flow rate of $50 \mathrm{~mL} / \mathrm{min}$ was fed in front of the GC inlet to measure the total flow rate of the effluent gas. An oscilloscope that was equipped with one voltage probe (Tektronix P6015A 10FT) and one current probe (TCPA300) was used to measure the power dissipation during spark discharge. In plasma-catalysis system, one quartz holder with an inner diameter of $8 \mathrm{~mm}$ is installed to prevent the catalyst from flopping over the gap as presented in Fig. 1 (b). The amount of BZT packed into the plasma reactor is $0.5 \mathrm{~g}$. All experimental data were obtained and recorded when the reactions reached a steady-state and measurements were made twice to yield a relative deviation of less than $10 \%$ and the experimental tests were performed at atmospheric pressure. In addition, the amount of coke deposited is estimated by measuring the weight difference of reactor after reforming process. The effluent volumetric flow rate $\left(\mathrm{Q}_{\text {eff }}\right.$, equation (3)), power dissipation $(\mathrm{P}$, 
equation (4)), $\mathrm{CH}_{4}$ and $\mathrm{CO}_{2}$ conversions $\left(\mathrm{X}_{\mathrm{CH}_{4}}\right.$ and $\mathrm{X}_{\mathrm{CO}_{2}}$, equation (5) and (6)), $\mathrm{H}_{2}$ and $\mathrm{CO}$ selectivities $\left(\mathrm{S}_{\mathrm{H}_{2}}\right.$ and $\mathrm{S}_{\mathrm{CO}}$, equation (7) and (8)), carbon balance (CB, equation (9)) and specific energy (SE, equation (10)) are defined as follows.

Effluent volumetric flow rate:

$Q_{\text {eff }}\left(\frac{\mathrm{mL}}{\min }\right)=\frac{Q_{\mathrm{N}_{2}, \text { inf }} \cdot \mathrm{C}_{N_{2}, \text { inf }}}{C_{N_{2}, \text { eff }}}$

$\mathrm{Q}_{\mathrm{N}_{2} \text {,inf }}$ is the $\mathrm{N}_{2}$ volumetric flow rate in influent ( $\mathrm{mL} / \mathrm{min}$ ) while $C_{N_{2}, \text { inf }}$ and $C_{N_{2}, \text { eff }}$ are $\mathrm{N}_{2}$ concentrations in influent and effluent (\%), respectively.

Power dissipation:

$P(W)=\int_{t=0}^{T} V(t) I(t) d t$

$\mathrm{V}(\mathrm{t})$ is the voltage applied generated to plasma $(\mathrm{V}), \mathrm{I}(\mathrm{t})$ is the current $(\mathrm{A})$ and $\mathrm{t}$ is the total discharge time (s).

Conversions of reactants:

$\mathrm{X}_{\mathrm{CH}_{4}}(\%)=\frac{\left[\mathrm{CH}_{4}\right]_{\text {inf }}-\left[\mathrm{CH}_{4}\right]_{\text {eff }}}{\left[\mathrm{CH}_{4}\right]_{\text {inf }}}$

$X_{\mathrm{CO}_{2}}(\%)=\frac{\left[\mathrm{CO}_{2}\right]_{\text {inf }}-\left[\mathrm{CO}_{2}\right]_{e f f}}{\left[\mathrm{CO}_{2}\right]_{\text {inf }}}$

$\left[\mathrm{CH}_{4}\right]_{\text {inf }},\left[\mathrm{CH}_{4}\right]_{\text {eff, }},\left[\mathrm{CO}_{2}\right]_{\text {inf }}$ and $\left[\mathrm{CO}_{2}\right]_{\text {eff }}$ are the $\mathrm{CH}_{4}$ and $\mathrm{CO}_{2}$ molar flow rates in influent and effluent ( $\mathrm{mmol} / \mathrm{min})$, respectively.

Selectivities of products:

$S_{\mathrm{H}_{2}}(\%)=\frac{\left[\mathrm{H}_{2}\right]_{\text {eff }}}{2 *\left(\left[\mathrm{CH}_{4}\right]_{\text {inf }}-\left[\mathrm{CH}_{4}\right]_{\text {eff }}\right)}$

$S_{C O}(\%)=\frac{\left[\mathrm{CO}_{e f f}\right.}{\left[\mathrm{CO}_{2}\right]_{\text {inf }}-\left[\mathrm{CO}_{2}\right]_{e f f}+\left[\mathrm{CH}_{4}\right]_{\text {inf }}-\left[\mathrm{CH}_{4}\right]_{e f f}}$

$S_{C_{\mathrm{x}} H_{\mathrm{y}}}(\%)=\frac{x *\left[\mathrm{C}_{\mathrm{x}} \mathrm{H}_{y}\right]_{e f f}}{\left[\mathrm{CH}_{4}\right]_{\text {inf }}-\left[\mathrm{CH}_{4}\right]_{e f f}}$

$\left[\mathrm{H}_{2}\right]_{\text {eff, }}[\mathrm{CO}]_{\text {eff }}$ and $\left[\mathrm{C}_{\mathrm{x}} \mathrm{H}_{\mathrm{y}}\right]_{\text {eff }}$ are the $\mathrm{H}_{2}, \mathrm{CO}$ and hydrocarbons molar flow rates in effluent ( $\mathrm{mmol} / \mathrm{min})$, respectively. 
Carbon balance:

$\mathrm{CB}(\%)=\frac{[\mathrm{C}]_{e f f}}{[\mathrm{C}]_{\text {inf }}}=\frac{\left[\mathrm{CO}_{2}\right]_{\text {eff }}+\left[\mathrm{CH}_{4}\right]_{\text {eff }}+[\mathrm{COO}]_{\text {eff }}+x *\left[\mathrm{C}_{\mathrm{x}} \mathrm{H}_{y}\right]_{\text {eff }}+[\text { Coke }]}{\left[\mathrm{CO}_{2}\right]_{\text {inf }}+\left[\mathrm{CH}_{4}\right]_{\text {inf }}}$

$[C]_{\text {inf }}$ and $[C]_{\text {eff }}$ are the molar flow rates of carbon atom in influent and effluent $(\mathrm{mmol} / \mathrm{min})$, respectively, and $[$ Coke $]$ is the amount of coke generated per minute $(\mathrm{mmol} / \mathrm{min})$, i.e. the weight difference of electrodes before and after reforming divided by operation period.

Specific energy:

$\mathrm{EE}\left(\frac{\mathrm{MJ}}{\mathrm{mol}}\right)=\frac{E_{t}}{\mathrm{~N}_{H_{2}+C O}}=\frac{P}{4.63 \cdot\left(\left[H_{2}\right]_{e f f}+[\mathrm{CO}]_{e f f}\right)}$

$\mathrm{N}_{\mathrm{H}_{2}+C O}$ is moles of $\mathrm{H}_{2}$ and $\mathrm{CO}$ produced within time $\mathrm{t}(\mathrm{mol}), E_{t}$ is the energy dissipation within time $\mathrm{t}(\mathrm{MJ})$ and $\mathrm{P}$ is the power consumption.

\section{Results and discussion}

A. Characterization of ferroelectric

Figure 2 presents the XRD results of C-BZT and C-BZT-P. The characteristic peaks at $22.2^{\circ}, 23.9^{\circ}, 31.7^{\circ}, 39.2^{\circ}, 45.4^{\circ}, 51.2^{\circ}, 56.1^{\circ}, 65.9^{\circ}, 70.4^{\circ}, 75.2^{\circ}, 79.5^{\circ}, 83.5^{\circ}$ and $92.3^{\circ}$ reveal that the ferroelectric had a tetragonal perovskite structure. Table 1 presents the lattice parameters of C-BZT and C-BZT-P, calculated from the XRD results, which demonstrate that with the partial substitution of $\mathrm{Zr}$, perovskite $\mathrm{BaTiO}_{3}$ undergoes a cubic to tetragonal phase transformation. As a result, $\mathrm{BaTiO}_{3}$ and $\mathrm{BaZr}_{0.05} \mathrm{Ti}_{0.95} \mathrm{O}_{3}$ belong to the space group of $\mathrm{Pm} \overline{3 \mathrm{~m}}$ and $\mathrm{P} 4 \mathrm{~mm}$, respectively. Previous studies have indicated that a ferroelectric with a tetragonal phase has a high dielectric constant and so exhibits high remnant polarization [33]. Moreover, the XRD results for C-BZT and C-BZT-P are very similar, indicating that the crystalline structure of the ferroelectric is stable during electron bombardment.

Table 2 presents the results of nitrogen adsorption-desorption of C-BZT and 
C-BZT-P. The specific surface areas of C-BZT and C-BZT-P are 7.77 and $16.65 \mathrm{~m}^{2} / \mathrm{g}$, respectively, while the average pore diameters of C-BZT and C-BZT-P are 5.3 and 4.8 $\mathrm{nm}$, respectively. The specific surface area of C-BZT is close to that of typical perovskite $\left(\sim 10 \mathrm{~m}^{2} / \mathrm{g}\right)$ whereas C-BZT-P has a higher specific surface area, because that surface morphology is altered during discharge. The average pore diameters of C-BZT and C-BZT-P are those of mesopores, which are effective in $\mathrm{CO}_{2}$ and $\mathrm{CH}_{4}$ adsorption. Microdischarges can be induced in pores of appropriate size, depending on the Debye length of the plasma process. For plasmas at atmospheric-pressure, the Debye length is approximately $50 \mathrm{~nm}$ and a pore diameter of greater than $5 \mathrm{~nm}$ can induce microdischarges [37].

Figure 3 presents $\mathrm{Ba} 3 \mathrm{~d}, \mathrm{Zr} \mathrm{3d}$, Ti $2 \mathrm{p}$ and $\mathrm{O}$ 1s XPS spectra. In the Ba $3 \mathrm{~d}$ spectrum of C-BZT, peaks at 780.2 and $795.4 \mathrm{eV}$ correspond to spin-orbital splitting of $\mathrm{Ba}^{2+} 3 \mathrm{~d}_{5 / 2}$ and $3 \mathrm{~d}_{3 / 2}$, which are bonded to $\mathrm{O}$ atoms. After discharge, two peaks are shifted to 781.4 and $796.7 \mathrm{eV}$, respectively, as presented in Fig 3 (a), revealing that the surface charge accumulates during discharge. XRD results indicate that crystalline structure remains stable during discharge so the phase transformation and further interactions among metal ions are negligible. Figure 3 (b) indicates that the $\mathrm{Zr}^{4+}$ ion $3 \mathrm{~d}_{3 / 2}$ bonding energy are shifted from 177.1 to $177.9 \mathrm{eV}$ after discharge. Figure 3 (c) displays $\mathrm{Ti}^{4+} 2 \mathrm{p}_{3 / 2}$ and $2 \mathrm{p}_{1 / 2}$ bonds with $\mathrm{O}$ ions and the corresponding peaks are shifted from 457.1 and $463.1 \mathrm{eV}$ to 459.8 and $465.5 \mathrm{eV}$, respectively. The shifting of the Ti-O bonding energy exceeds that of $\mathrm{Ba}-\mathrm{O}$ and $\mathrm{Zr}-\mathrm{O}$ bonding energies because the Ti-O interaction is the strongest. The $\mathrm{O} 1 \mathrm{~s}$ spectrum of C-BZT in Figure 3 (d) has a single peak at $531.4 \mathrm{eV}$, which corresponds to the $1 \mathrm{~s}_{1 / 2}$ bonding energy. Discharge splits the $\mathrm{O} 1 \mathrm{~s}$ spectrum into two oxygen peaks, $\mathrm{O}_{\mathrm{L}}$ and $\mathrm{O}_{\mathrm{H}}$ [38]. The $\mathrm{O}_{\mathrm{L}}$ peak at 531.2 $\mathrm{eV}$ is associated with the lattice oxygen that is bonded to $\mathrm{Ba}, \mathrm{Zr}$ and $\mathrm{Ti}$. The shift of the $\mathrm{O}_{\mathrm{L}}$ peak to a lower bonding energy can be attributed to surface charge, which 
results in repulsive $\mathrm{O} 1 \mathrm{~s}$ bonding. The $\mathrm{O}_{\mathrm{H}}$ peak at $533.3 \mathrm{eV}$ is associated with chemisorbed hydroxyl oxygen species including $\mathrm{O}^{-}$and $\mathrm{OH}^{-}$that are generated during discharge, indicating that BZT acts as a catalyst. Adsorbed $\mathrm{O}^{-}$on the surface of BZT is a strong oxidizing agent which reacts with $\mathrm{CH}_{\mathrm{x}}(\mathrm{x}=1 \sim 4)$ to generate $\mathrm{H}$ atom. Hence, $\mathrm{CO}_{2}$ dissociation may yields $\mathrm{O}^{-}$which can further dissociate $\mathrm{CH}_{4}$.

Figures 4 (a) and (b) present SEM images of C-BZT, in which grains are seen clearly with a size distribution of $40-200 \mathrm{~nm}$, and many mesopores are observed within the C-BZT powder. After discharge, the grains are observed more uniform and smaller, ranging from 20 to $30 \mathrm{~nm}$, indicating that electron bombardment during discharge crushes the grains into many smaller crystalline grains on the C-BZT-P surface. Therefore, the specific surface area becomes larger upon discharge and the BET and SEM results are consistent with each other. Table 2 presents the EDS results for C-BZT and C-BZT-P, and reveals that the ratio of the metals present is close to the stoichiometric ratio of a ferroelectric.

B. Influence of GHSV on reforming efficiency

Figure 5 (a) and (b) plot the dependences of the $\mathrm{CH}_{4}$ and $\mathrm{CO}_{2}$ conversions on GHSV. Both $\mathrm{CH}_{4}$ and $\mathrm{CO}_{2}$ conversions decrease as the GHSV increases, as presented in Table 3. This result is attributed to a reduction of the retention time and, therefore, the number of effective collisions. Plasma reactor that is packed with C-BZT yields better $\mathrm{CH}_{4}$ and $\mathrm{CO}_{2}$ conversions than the F-BZT packed bed because the higher voidage in the packed bed, inducing stronger microdischarges. Montoro-Damas et al. (2015) observed a similar result, when they used $\mathrm{PbZr}_{\mathrm{x}} \mathrm{Ti}_{1-\mathrm{x}} \mathrm{O}_{3}$ (PZT) with two different diameters (0.5 $2 \mathrm{~mm}$ and $2 \sim 3 \mathrm{~mm}$, respectively) for DRM, and found that packing a ferroelectric with a larger diameter into plasma reactor results in higher 
methane conversion and thus greater hydrogen production per kilowatt-hour [38]. Zhang et al. (2016) investigated the relationship between pore size and electron density and the results show that a larger pore size results in higher electron density. In packed-bed reactor, voidage plays a similar role to pore since their boundary, atmosphere and electrical properties are close to each other. Hence, size of voidage influences microdischarge and in this work C-BZT is more suitable than F-BZT [37].

Figures 5 (c) and (d) present the effects of GHSV on the selectivities of $\mathrm{H}_{2}$ and $\mathrm{CO} . \mathrm{H}_{2}$ selectivity increases while $\mathrm{CO}$ selectivity decreases with increasing GSHV, as presented in Table 3 . The increase of $\mathrm{H}_{2}$ selectivity is attributable to the enhancement in $\mathrm{CH}_{\mathrm{x}}(\mathrm{x}=1 \sim 4)$ dissociation by the collisions of reactive $\mathrm{O}$ atoms, which are generated via $\mathrm{CO}_{2}$ and $\mathrm{CO}$ dissociation. Similarly, the decrease of $\mathrm{CO}$ selectivity can be attributed to the dissociation of $\mathrm{CO}$ into $\mathrm{C}$ and $\mathrm{O}$ atom.

Figure 5 (e) presents carbon balance, and carbon balance decreases with increasing GHSV. A ferroelectric increases the carbon balance by increasing the $\mathrm{CO}$ selectivity and inhibits carbon deposition. Packing the ferroelectric into plasma reactor reduces carbon deposition because the polarization of the ferroelectric whose direction opposes the electric field induces an ionic wind and a repulsive force, extending the operating time. It is noticed that coke selectivity with various GHSV is nearly identical. Hence, the influence of coke deposition on carbon balance is insignificant. Also, coke selectivity for plasma reactor without and packed with ferroelectric are 3.5 and $2.2 \%$, respectively.

Figure 5 (f) shows the specific energy achieved with various GHSVs. Specific energy decreases with decreasing GHSV. As the GHSV decreases, power dissipated to $\mathrm{CH}_{4}$ and $\mathrm{CO}_{2}$ molecules decreased because of significantly increased molar flow rate. When the GHSV is lower than $51,000 \mathrm{hr}^{-1}$, power dissipation in ferroelectric-packed reactor is significantly higher than the plasma reactor without ferroelectric, leading to 
lower energy utilization and thus higher specific energy. When the GHSV exceeds $51,000 \mathrm{hr}^{-1}$, the specific energies in ferroelectric-packed reactors are lower than plasma reactor without ferroelectric due to better energy dissipation on $\mathrm{CH}_{4}$ and $\mathrm{CO}_{2}$ molecules and hence the energy consumption is decreased.

C. Influence of applied voltage on reforming efficiency

Figure 6 shows the dependences of the conversions, selectivities, carbon balance and specific energy on applied voltage. Both $\mathrm{CH}_{4}$ and $\mathrm{CO}_{2}$ conversions increase with the applied voltage as presented in Table 3 . Increasing the applied voltage leads to a higher electron density inside the reactor, so the numbers of electrons with sufficient kinetic energy is increased. Therefore, $\mathrm{CH}_{4}$ and $\mathrm{CO}_{2}$ conversions increased. The C-BZT packed bed improves GHG conversions more than does the F-BZT packed bed because the voidage is higher, and so the voids contain a higher density of electrons, another study found similar results [38]

Figures 6 (c) and (d) show the effect of applied voltage on the selectivities of $\mathrm{H}_{2}$ and $\mathrm{CO}$. The reactors packed that are with F-BZT and C-BZT have higher syngas selectivities than that without BZT packed bed because more active species including $\mathrm{O}\left({ }^{1} \mathrm{~S}\right), \mathrm{O}\left({ }^{3} \mathrm{P}\right)$ and $\mathrm{CO}\left(\mathrm{a}^{3} \Pi\right)$ are generated. A higher power consumption leads to a higher electron density and, therefore the generation of more active species. These active species can collide with $\mathrm{CH}_{\mathrm{x}}$ to generate $\mathrm{H}$ and further increase $\mathrm{H}_{2}$ selectivity. The higher $\mathrm{CO}$ selectivities in BZT packed beds is attributable to the formation of more active species, $\mathrm{O}\left({ }^{1} \mathrm{~S}\right), \mathrm{O}\left({ }^{3} \mathrm{P}\right)$, favoring the oxidation of the generated carbon to form $\mathrm{CO}$.

Figure 6 (e) shows the decrease in carbon balance as the applied voltage increases. The lower carbon balance at higher power consumption is attributable to greater $\mathrm{CH}_{4}$ 
dissociation, resulting in higher carbon deposition. Moreover, applied voltage has nearly no influence on the coke deposition and resulting in identical coke deposition rate. Higher power consumption results in better GHG conversions. However, increasing the applied voltage does not necessarily decrease specific energy, as presented in Figure 6 (f).

\section{Plasma performance of plasma in BZT packed bed}

Table 4 compares corona, DBD, microwave, gliding arc and spark discharge plasma reactors for syngas generation. Operating conditions including GHSV and power consumption can be varied, depending upon the type of reactor. Generally, power consumptions are in a range of tens to hundreds of watt, and those plasmas are classified as non-thermal plasmas. DBD is frequently investigated for dry reforming of methane since the electron in DBD reactor can acquire kinetic energy up to $10 \mathrm{eV}$, which is higher than other types of plasma. However, specific energy obtained with DBD is relatively high, possibly due to the lower density in DBD reactor compared with other plasma reactors including spark discharge and gliding arc. In the case of corona discharge, specific energy is also higher than spark discharge and this may be attributed to short residence time of reactants in discharge volume. Microwave has a higher treating capacity and higher energy consumption but its major obstacle is the high capital cost. Overall, gliding arc and spark discharge are of better syngas generation efficiency. Table 4 implies that electron energy is not necessarily to be high $(\sim 10 \mathrm{eV})$ and the key to enhance reforming efficiency is effective generation of vibrational excited species to further stimulate $\mathrm{CO}_{2}$ and $\mathrm{CH}_{4}$ dissociations. Also, the specific energies that are measured in this study lower than those of previously investigated reactors, showing good potential of the system developed for application.

Figure 7 shows the effect of packing a ferroelectric into a plasma reactor. Without 
discharge, the ferroelectric exhibits no polarization and no electrostatic force exists between electrons and ions. With an external electric field, $\mathrm{Ba}^{2+}, \mathrm{Ti}^{4+}$ and $\mathrm{Zr}^{4+}$ cations in the ferroelectric are attracted by the external electrostatic force from the DC power supply and the anions $\left(\mathrm{O}^{-2}\right)$ are attracted by the external electrostatic force from the ground electrode, causing the cations and anions to move in opposite directions, resulting in polarization. The polarization of a conventional insulator disappears as the external electric field is removed. A ferroelectric retains a portion of its polarization, called the remnant polarization, owing to internal forces in its crystalline structure [39]-[42]. This remnant cannot be eliminated since the external electric field has a single orientation (DC power), so the direction of polarization is fixed once the ferroelectric is polarized. After polarization, the ferroelectric surface has opposing positive and negative charges. Positive charges electrostatically attract anions, including free electrons, $\mathrm{O}^{-}$and other negative ions. Therefore, free electrons are accelerated by polarization, increasing their kinetic energy [49]. Free electrons with higher kinetic energy in a ferroelectric-packed bed favor vibrational excitation, dissociation and ionization, which can be further increased by ferroelectric polarization and increasing the electron density in discharge region. Packing the spark discharge reactor with ferroelectric increases the power consumption from $26.6 \mathrm{~W}$ to 39.3 W, resulting in the increase of both $\mathrm{CH}_{4}$ and $\mathrm{CO}_{2}$ conversions. In a ferroelectric-packed bed, the ferroelectric acts as third body, inducing three-body exothermic recombination, increasing higher $\mathrm{H}_{2}$ selectivity. $\mathrm{CO}$ generation, $\mathrm{CO}_{2}$ dissociation and the oxidation of coke are all enhanced.

Notably, introducing BZT into the plasma reactor increases its operating duration by inhibiting the deposition of coke. In a plasma reactor, coke can be deposited on the electrode, inhibiting discharge. A higher GHSV leads to faster coke deposition and, therefore, a shorter operating period. In DRM that is performed with a GHSV of 
$85,000 \mathrm{hr}^{-1}$ without BZT, coke deposition limits the discharge period to 30 minutes ( 1.5 hours with GHSV of $8,500 \mathrm{hr}^{-1}$ ). Introducing BZT into the plasma reactor can extend the discharge duration from half an hour to over 1 hour for two reasons: the first one is that the existence of catalyst inhibits carbon deposition on electrodes and the other one is the repulsion between BZT and carbon. The BZT packed bed induces a surface charge on a ferroelectric, generating a repulsive force on carbon-containing functional groups, which inhibits the deposition of carbon on electrode surfaces. Moreover, BZT packed in plasma reactor can sustain for at least three stable reaction cycles (> 3 hours). In other words, introducing BZT not only increases the conversion of GHGs and the syngas generation efficiency but also extends the operating period of the plasma reactor.

\section{Conclusions}

In this work, BZT with a perovskite structure and ferroelectric property is prepared with sol-gel method and is introduced into a spark discharge reactor to evaluate the performance of hybrid plasma catalysis system for dry reforming of methane. The result of BZT characterization including $\mathrm{N}_{2}$ adsorption and desorption isotherm, SEM and XPS indicate that during discharge, plasma can influence morphology, surface structure and chemistry of BZT. Also, remnant polarization of BZT retains after discharge and plays an important role in reforming. Results of dry reforming indicate that with the introduction of BZT into the plasma reactor, $\mathrm{CH}_{4}$ and $\mathrm{CO}_{2}$ conversions increase from 52.5 and $49.4 \%$ to 84.2 and $77.1 \%$, respectively, indicating that combining spark discharge reactor with BZT induces synergistic effects and reduces specific energy from 0.268 to $0.218 \mathrm{MJ} / \mathrm{mol}$.

For scaling up the system, two requirements need to be fulfilled. The first concern 
is the stability of the hybrid system. To extend the operating duration of this reforming system, byproduct formation such as coke must be minimized. The other one is how to increase the dimension of reforming system, including plasma reactor, ferroelectric packed bed and power generator. Further investigation is needed towards these two objectives.

\section{Acknowledgements}

The authors would like to thank the National Central University and the Ministry of Science and Technology, Taiwan, for financially supporting this research under Contract "Aim for the Top University Plan" and MOST 102-2221-E-008-003-MY3. The authors also express their gratitude to Dr. Chung-Jen Tseng and Mr. Jhe-Wei Jhuang in Department of Energy Engineering, NCU, for their assistance in preparing ferroelectric. 
Reference

[1]A. F. Ghoniem. Needs, resources and climate change: Clean and efficient conversion technologies. Prog. Energy. Combust. Sci., 2011, 37, 15-51.

[2]R. M. Cuéllar-Franca, A. Azapagic. Carbon capture, storage and utilisation technologies: A critical analysis and comparison of their life cycle environmental impacts. J. $\mathrm{CO}_{2}$ Util., 2015, 9, 82-102.

[3]M. M. F. Hasan, E. L. First, F. Boukouvala, C. A. Floudas. A multi-scale framework for $\mathrm{CO}_{2}$ capture, utilization, and sequestration: CCUS and CCU. Comput. Chem. Eng., 2015, 81, 2-21.

[4]I. Omae. Recent developments in carbon dioxide utilization for the production of organic chemicals. Coordin. Chem. Rev., 2012, 256, 1384-1405.

[5]R. Y. Chein, Y. C. Chen, J. N. Chung. Thermodynamic analysis of dry reforming of $\mathrm{CH}_{4}$ with $\mathrm{CO}_{2}$ at high pressures. J. Nat. Gas Sci. Eng., 2015, 26, 617-629.

[6]Z. A. Allah, J. C. Whitehead. Plasma-catalytic dry reforming of methane in an atmospheric pressure AC gliding arc discharge. Catal. Today, 2015, 256, 76-79.

[7]K. L. Pan, W. C. Chung, M.B. Chang. Dry reforming of $\mathrm{CH}_{4}$ with $\mathrm{CO}_{2}$ to generate syngas by combined plasma catalysis IEEE Tran. Plasma Sci., 2014, 42, 38093819.

[8]J. L. Casci, C. M. Lok, M. D. Shannon. Fischer-Tropsch catalysis: The basis for an emerging industry with origins in the early 20th Century. Catal. Today, 2009, 145, $38-44$.

[9]M.A. Mujeebu. Hydrogen and syngas production by superadiabatic combustion A review. Appl. Energ., 2016, 173, 210-224.

[10] H. Wu, G. Pantaleo, V. L. Parola, A. M. Vanezia, X. Collard, C. Aprile, L.F. Liotta. Bi- and trimetallic Ni catalysts over $\mathrm{Al}_{2} \mathrm{O}_{3}$ and $\mathrm{Al}_{2} \mathrm{O}_{3}-\mathrm{MO}_{\mathrm{x}}(\mathrm{M}=\mathrm{Ce}$ or $\mathrm{Mg})$ oxides for methane dry reforming: Au and Pt additive effects. Appl. Catal. B: 
EAnviron Environ., 2014, 156-157, 350-361.

[11] I. Tankov, K. Arishtirova, J. M. C. Bueno, S. Damyanova. Surface and structural features of $\mathrm{Pt} / \mathrm{PrO}_{2}-\mathrm{Al}_{2} \mathrm{O}_{3}$ catalysts for dry methane reforming. Appl. Catal. A: General, 2014, 474, 135-148.

[12] A. Horváth, L. Guczi, A. Kocsonya, G. Sáfrán, V. La Parola, L. F. Liotta, G. Pantaleo, A. M. Venezia. Fischer-Tropsch synthesis: A review of the effect of CO conversion on methane selectivity. Appl. Catal. A: General, 2013, 468, 250-259.

[13] B. Nematollahi, M. Rezaei, M. Khajenoori. Combined dry reforming and partial oxidation of methane to synthesis gas on noble metal catalysts. Int. J. Hydrogen Energy, 2011, 36, 2969-2978.

[14] M. Usman, W. M. A. W. Daud, H. F. Abbas. Dry reforming of methane: Influence of process parameters-A review. Renew. Sustain. Energy Rev., 2015, 45, $710-744$.

[15] R. Benrabaa, A. Löfberg, J. G. Caballero, E. Bordes-Richard, A. Rubbens, R. Vannier, H. Boukhlouf, A. Barama. Sol-gel synthesis and characterization of silica supported nickel ferrite catalysts for dry reforming of methane. Catal. Commun., $2015,58,127-131$.

[16] S. Sengupta, G. Deo. Modifying alumina with $\mathrm{CaO}$ or $\mathrm{MgO}$ in supported $\mathrm{Ni}$ and $\mathrm{Ni}-\mathrm{Co}$ catalysts and its effect on dry reforming of $\mathrm{CH}_{4} . \mathrm{J} \mathrm{CO}_{2}$ Util., 2015, 10, $67-$ 77.

[17] Z. Alipour, M. Rezaei, F. Meshkani. Effect of alkaline earth promoters (MgO, $\mathrm{CaO}$, and $\mathrm{BaO}$ ) on the activity and coke formation of Ni catalysts supported on nanocrystalline $\mathrm{Al}_{2} \mathrm{O}_{3}$ in dry reforming of methane. J. Ind. Eng. Chem., 2014, 20, $2858-2863$.

[18] Y. J. Su, K. L. Pan, M. B. Chang. Modifying perovskite-type oxide catalyst $\mathrm{LaNiO}_{3}$ with $\mathrm{Ce}$ for carbon dioxide reforming of methane. Int. J. Hydrogen Energy, 
2014, 39, 4917-4925.

[19] A. Aziznia, H. R. Bozorgzadeh, N. Seyed-Matin, M. Baghalha. A. Mohamadalizadeh. Comparison of dry reforming of methane in low temperature hybrid plasma-catalytic corona with thermal catalytic reactor over $\mathrm{Ni} / \gamma-\mathrm{Al}_{2} \mathrm{O}_{3} . J$. Nat. Gas Chem., 2012, 21, 466-475.

[20] S. Kameshima, K. Tamura, Y. Ishibashi, T. Nozaki. Pulsed dry methane reforming in plasma-enhanced catalytic reaction. Catal. Today, 2015, 256, 67-75.

[21] A. Wu, J. Yan, H. Zhang, M. Zhang, C. Du, X. Li. Study of the dry methane reforming process using a rotating gliding arc reactor. Int. J. Hydrogen Energy, 2014, 39, 17656-17670.

[22] S. A. Iwarere, V. J. Rohani, D. Ramjugernath, L. Fulcheri. Dry reforming of methane in a tip-tip arc discharge reactor at very high pressure. Int. J. Hydrogen Energy, 2015, 40, 3388-3401.

[23] X. Zhu, K. Li, J. L. Liu, X. S. Li, A. M. Zhu. Effect of $\mathrm{CO}_{2} / \mathrm{CH}_{4}$ ratio on biogas reforming with added $\mathrm{O}_{2}$ through an unique spark-shade plasma. Int. J. Hydrogen Energy, 2014, 39, 13902-13908.

[24] M. M. Moshrefi, F. Rashidi. Hydrogen production from methane by DC spark discharge: Effect of current and voltage. J. Nat. Gas. Sci. Eng., 2014, 16, 85-89.

[25] M. M. Moshrefi, F. Rashidi, H. R. Bozorgzadeh, M. E. Haghighi. Dry reforming of methane by DC spark discharge with a rotating electrode. Plasma Chem Plasma Process., 2013, 33, 453-466.

[26] Y. X. Zeng, X. B. Zhu, D. H. Mei, B. Ashford, X. Tu. Plasma-catalytic dry reforming of methane over $\gamma-\mathrm{Al}_{2} \mathrm{O}_{3}$ supported metal catalysts. Catal. Today., 2015, $256,80-87$.

[27] K. Li, J. L. Liu, X. S. Li, X. B. Zhu, A. M. Zhu. Post-plasma catalytic oxidative $\mathrm{CO}_{2}$ reforming of methane over Ni-based catalysts. Catal. Today., 2015, 256, 96- 
101.

[28] X. J. Tang, F. D. Feng, L. L. Ye, X. M. Zhang, Y. F. Huang, Z. Liu, K. P. Yan. Removal of dilute VOCs in air by post-plasma catalysis over Ag-based composite oxide catalysts. Catal. Today, 2013, 211, 39-43.

[29] J. V. Durme, J. Dewulf, C. Leys, H. V. Langenhove. Combining non-thermal plasma with heterogeneous catalysis in waste gas treatment: A review. Appl. Catal. B Environ., 2008, 78, 324-333.

[30] X. M. Tao, M. G. Bai, X. D. Li, H. L. Long, S.Y. Shang, Y. X. Yin. $\mathrm{CH}_{4}-\mathrm{CO}_{2}$ reforming by plasma - challenges and opportunities. Prog. Energ. Combust. Sci., $2011,37,113-124$.

[31] H. L. Chen, H. M. Lee, S. H. Chen, Y. Chao, M. B. Chang. Review of plasma catalysis on hydrocarbon reforming for hydrogen production-Interaction, integration, and prospects. Appl. Catal. B Environ., 2008, 85, 1-9.

[32] H. L. Chen, H. M. Lee, S. H. Chen, M. B. Chang, S. J. Yu, S. N. Li. Removal of volatile organic compounds by single-stage and two-stage plasma catalysis systems: A review of the performance enhancement mechanisms, current status, and suitable applications. Environ. Sci. Technol., 2009, 43, 2216-2227.

[33] E. W. Sun, W. W. Cao. Relaxor-based ferroelectric single crystals: Growth, domain engineering, characterization and applications. Prog. Meter. Sci., 2014, 65, $124-210$.

[34] S. J. Zhang, F. Li, X. N. Jiang, J. W. Kim, J. Luo, X. C. Geng. Advantages and challenges of relaxor- $\mathrm{PbTiO}_{3}$ ferroelectric crystals for electroacoustic transducers A review Prog. Meter. Sci., 2015, 68, 1-66.

[35] W. C. Chung, K. L. Pan, H. M. Lee, M. B. Chang. Dry reforming of methane with dielectric barrier discharge and ferroelectric packed-bed reactors. Energy Fuel., 2014,28, 7621-7631. 
[36] A. Y. Liu, J. Q. Xue, X. J. Meng, J. L. Sun, Z. M. Huang, J. H. Chu. Infrared optical properties of $\mathrm{Ba}\left(\mathrm{Zr}_{0.20} \mathrm{Ti}_{0.80}\right) \mathrm{O}_{3}$ and $\mathrm{Ba}\left(\mathrm{Zr}_{0.30} \mathrm{Ti}_{0.70}\right) \mathrm{O}_{3}$ thin films prepared by sol-gel method. Appl. Surf. Sci., 2008, 254, 5660-5663.

[37] Y. R. Zhang, K. V. Laer, E. C. Neyts, A. Bogaerts. Can plasma be formed in catalyst pores? A modeling investigation. Appl. Catal. B: Environ., 2016, 185,5667.

[38] A. M. Montoro-Damas, J. J. Brey, M. A. Rodríguez, A. R. González-Elipe, J. Cotrino. Plasma reforming of methane in a tunable ferroelectric packed-bed dielectric barrier discharge reactor. J. Power Sources, 2015, 296, 268-275.

[39] A. Psterson, H. T. Wong, Z. Liu, W. Ren, Z. G. Ye. Synthesis, structure and electric properties of a new lead-free ferroelectric solid solution of $(1-\mathrm{x}) \mathrm{BaTiO}_{3}-$ xBi( $\left.\mathrm{Zn}_{2 / 3} \mathrm{Nb}_{1 / 3}\right) \mathrm{O}_{3}$. Ceram. Int., 2015, 41, S57-S62.

[40] V. S. Puli, D. K. Pradhan, B. C. Riggs, D. B. Chrisey, R. S. Katiyar. Investigations on structure, ferroelectric, piezoelectric and energy storage properties of barium calcium titanate (BCT) ceramics J. Alloys Compd. 2014, 584, $369-373$.

[41] J. B. Xu, B. Shen, J. W. Zhai. Dielectric, ferroelectric and optical properties of $\mathrm{BaZr}_{0.2} \mathrm{Ti}_{0.8} \mathrm{O}_{3}$ thin films prepared by sol-gel-hydrothermal process J. Sol-Gel Sci. Technol., 2010, 55, 343-347.

[42] P. A. Jha, A. K. Jha. Enhancement of electrical properties and blue emission due to nanostructuring of $\mathrm{BaZr}_{0.05} \mathrm{Ti}_{0.95} \mathrm{O}_{3}$ ferroelectric ceramics. J. Mater. Sci. - Mater Electron., 2014, 25, 797-804.

[43] J. Q. Zhang, J. S. Zhang, Y. J. Yang, Q. Liu. Oxidative coupling and reforming of methane with carbon dioxide using a pulsed microwave plasma under atmospheric pressure. Energy Fuels, 2003, 17, 54-59.

[44] B. Fidalgo, A. Domínguez, J. J. Pis, J. A. Menéndez. Microwave-assisted dry 
reforming of methane. Int. J. Hydrogen Energy, 2008, 33, 4337-4344.

[45] M. W. Li, C. P. Liu, Y. L. Tian, G. H. Xu, F. C. Zhang, Y. Q. Wang. Effects of catalysts in carbon dioxide reforming of methane via corona plasma reactions. Energy Fuels, 2006, 20, 1033-1038.

[46] X. Tu, J.C. Whitehead. Plasma-catalytic dry reforming of methane in an atmospheric dielectric barrier discharge: Understanding the synergistic effect at low temperature. Appl. Catal. B Environ., 2012, 125, 439-448.

[47] Z. Bo, J. H. Yan, X. D. Li, Y. Chi, K. F. Cen. Plasma assisted dry methane reforming using gliding arc gas discharge: Effect of feed gases proportion. Int. J. Hydrogen Energy, 2008, 33, 5545-5553.

[48] X. S. Li, B. Zhu, C. Shi, Y. Xu, A. M. Zhu. Carbon dioxide reforming of methane in kilohertz spark-discharge plasma at atmospheric pressure. AIChE, 2011, $57,2854-2860$.

[49] W. C. Chung, M. B. Chang, Review of catalysis and plasma performance on dry reforming of $\mathrm{CH}_{4}$ and possible synergistic effects. Renew. Sustain. Energy Rev., 2016, 62, 13-31. 
Figure captions

Figure 1 Experimental setup of (a) reforming system and (b) discharge reactor with ferroelectric packed bed.

Figure $2 \mathrm{X}$-ray diffraction patterns of C-BZT- and C-BZT-P powder.

Figure 3 XPS spectra of (a) Ba, (b) Zr, (c) Ti and (d) O.

Figure 4 SEM images of (a), (b) C-BZT and (c) and (d) C-BZT-P powder.

Figure 5 Influence of ferroelectric size and GHSV on (a) $\mathrm{CH}_{4}$ conversion, (b) $\mathrm{CO}_{2}$ conversion, (c) $\mathrm{H}_{2}$ selectivity, (d) $\mathrm{CO}$ selectivity, (e) carbon balance and (f) specific energy. $\mathrm{CH}_{4} / \mathrm{CO}_{2}=1$, applied voltage $=13 \mathrm{kV}$, frequency $=20,000 \mathrm{~Hz}$ and discharge gap $=5 \mathrm{~mm}$.

Figure 6 Influence of ferroelectric size and applied voltage on (a) $\mathrm{CH}_{4}$ conversion, (b) $\mathrm{CO}_{2}$ conversion, (c) $\mathrm{H}_{2}$ selectivity, (d) $\mathrm{CO}$ selectivity, (e) carbon balance and (f) specific energy. $\mathrm{CH}_{4} / \mathrm{CO}_{2}=1$, flow rate $=200 \mathrm{~mL} / \mathrm{min}, \mathrm{GHSV}=85,000 \mathrm{~h}^{-1}$, frequency $=20,000 \mathrm{~Hz}$ and discharge gap $=5 \mathrm{~mm}$.

Figure 7 Mechanism of ferroelectric polarization and its effect on reforming. 

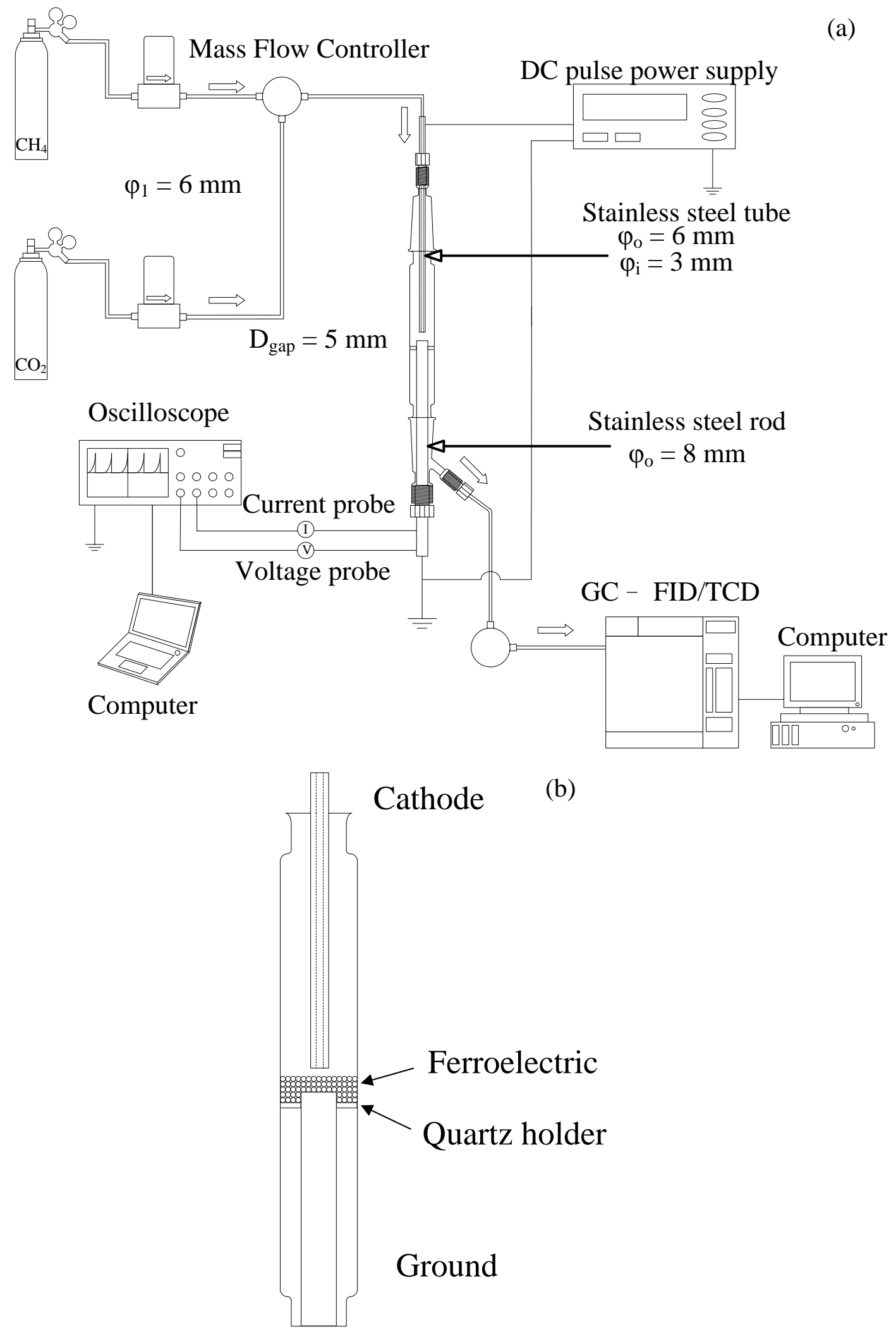

Fig.1 Experimental setup of (a) reforming system and (b) discharge reactor with ferroelectric packed bed. 


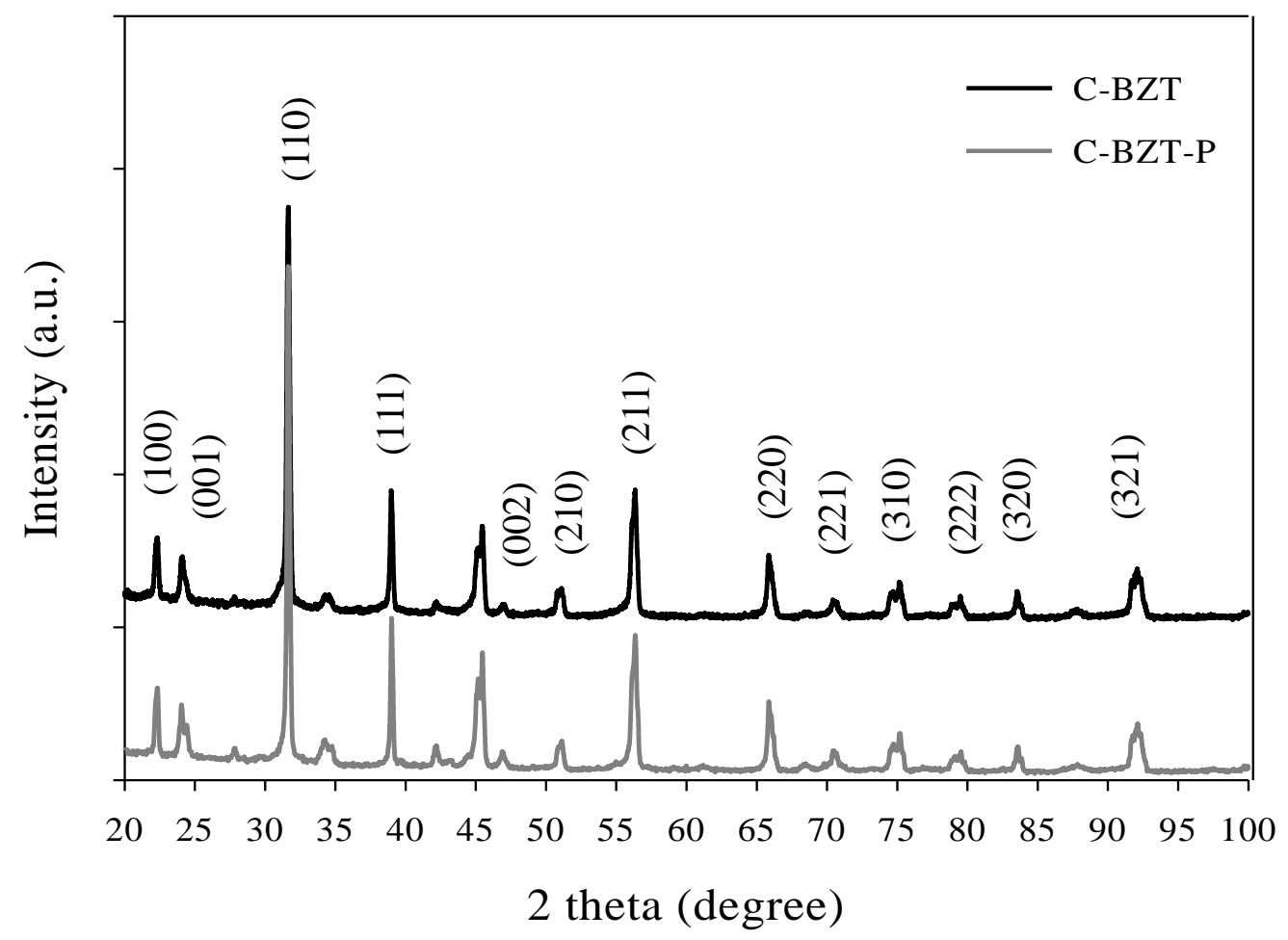

Fig. 2 X-ray diffraction patterns of C-BZT and C-BZT-P powder. 

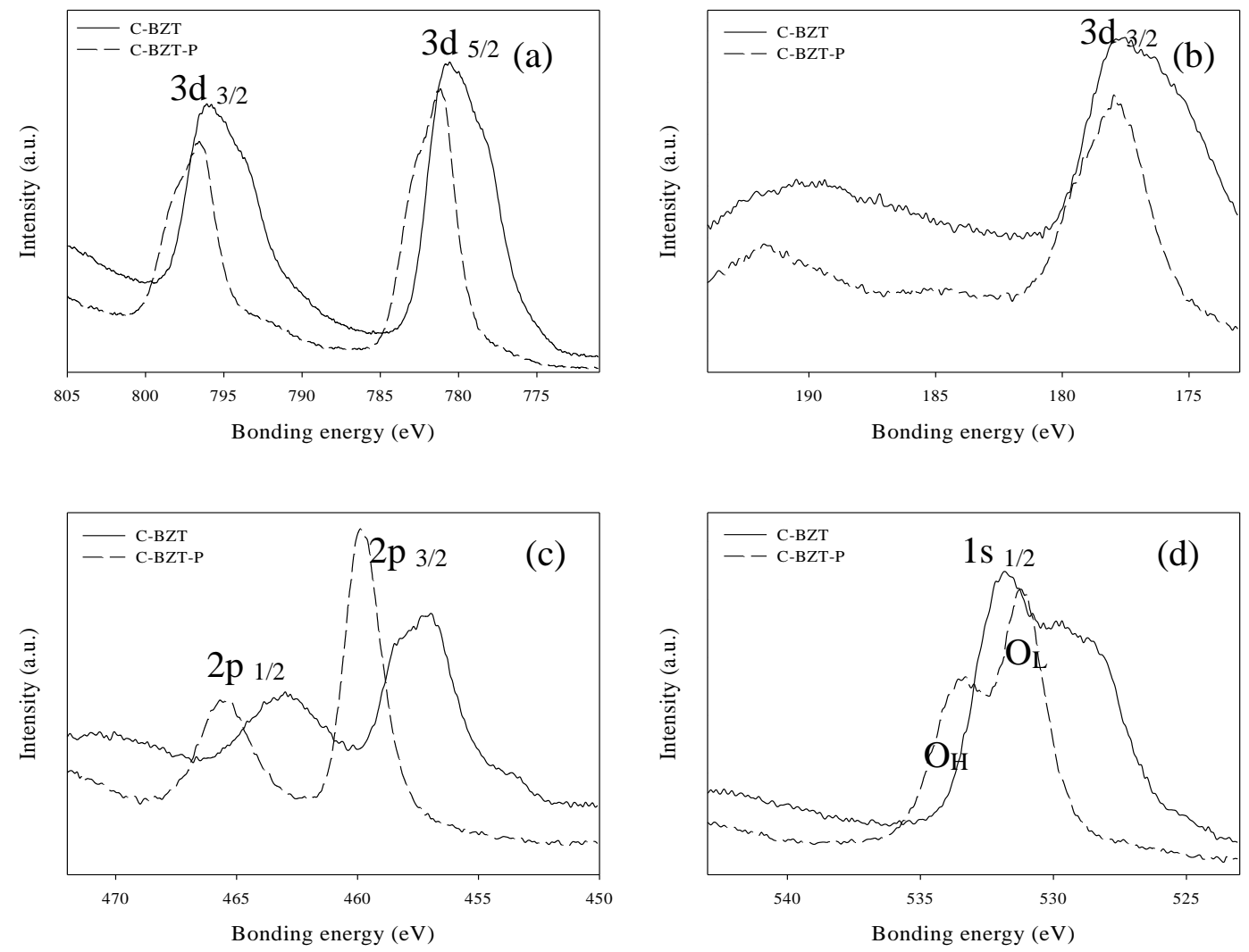

Fig. 3 XPS spectra of (a) Ba, (b) Zr, (c) Ti and (d) O. 

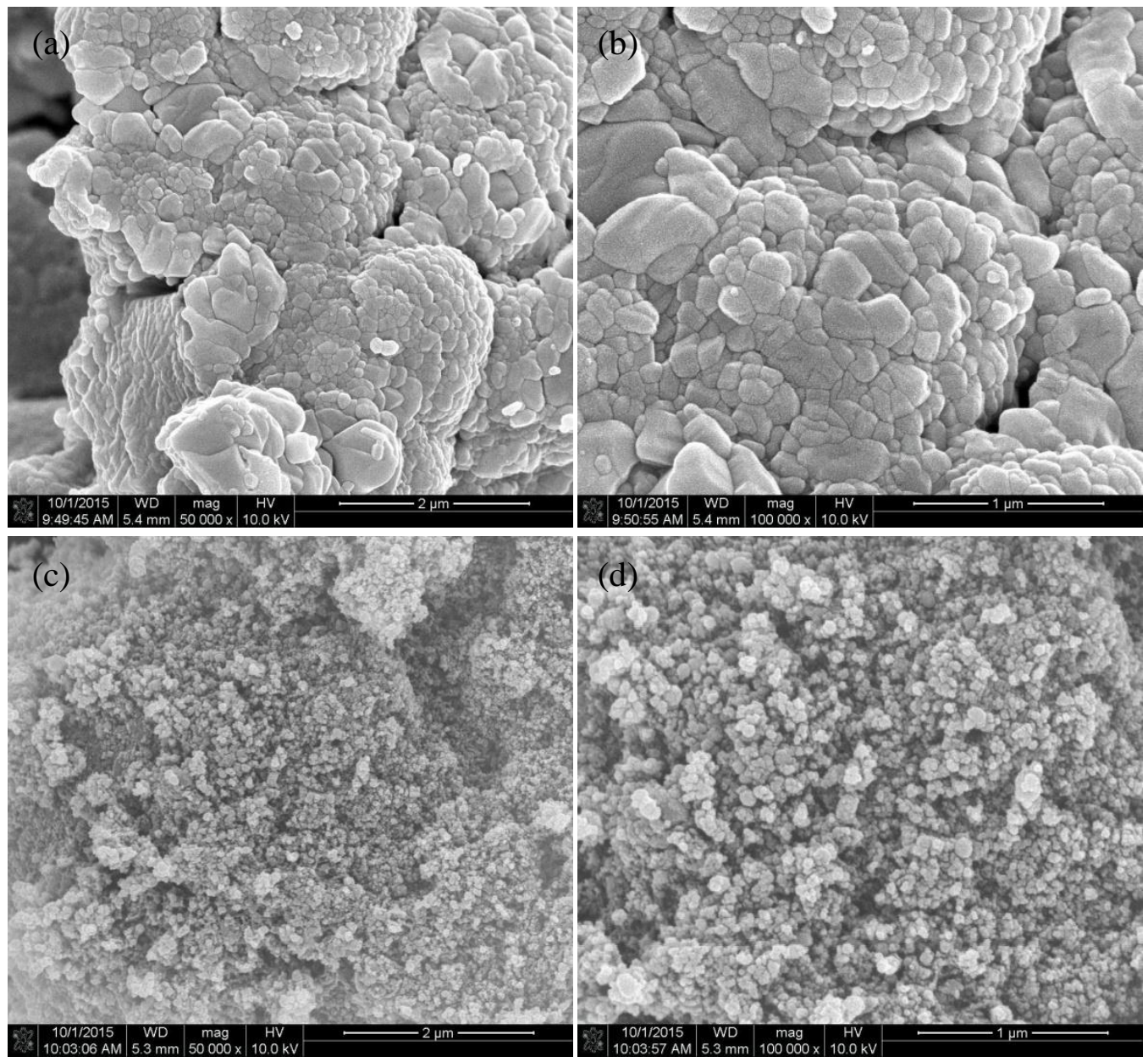

Fig. 4 SEM images of (a), (b) C-BZT and (c) and (d) C-BZT-P powder. 
(a)

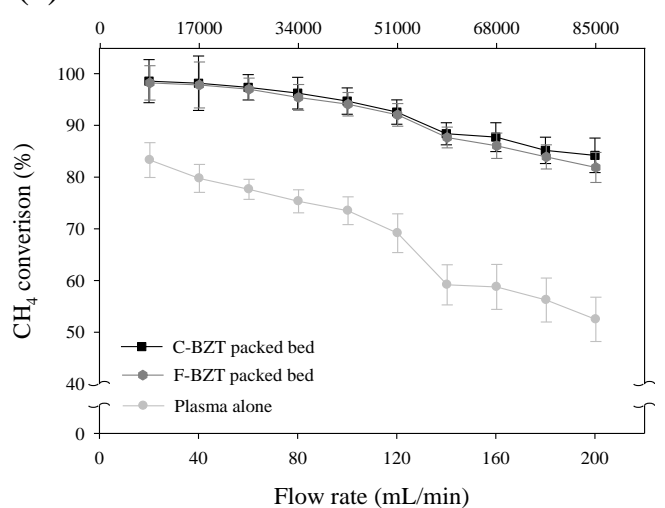

(c)

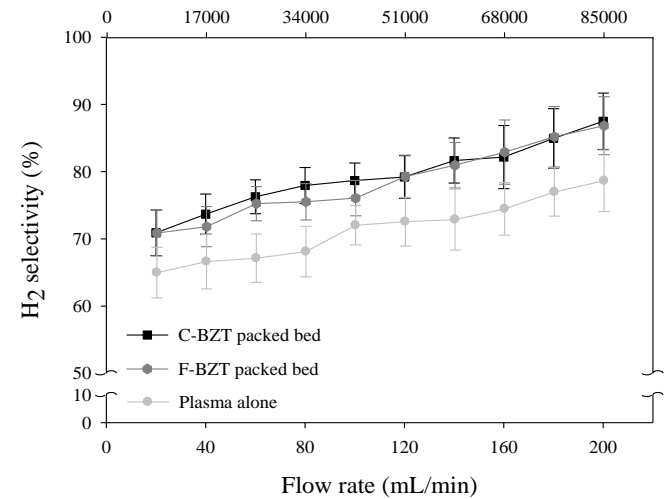

(e)

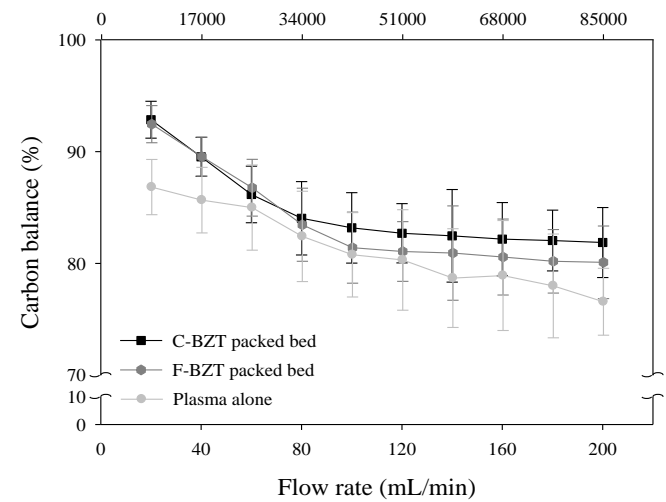

(b)

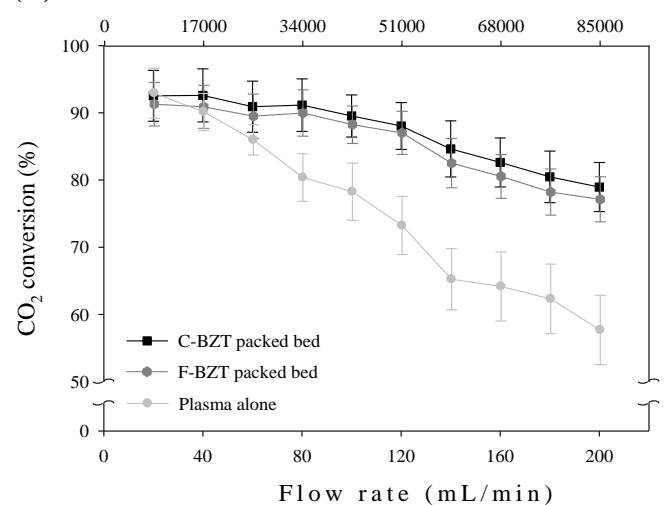

(d)

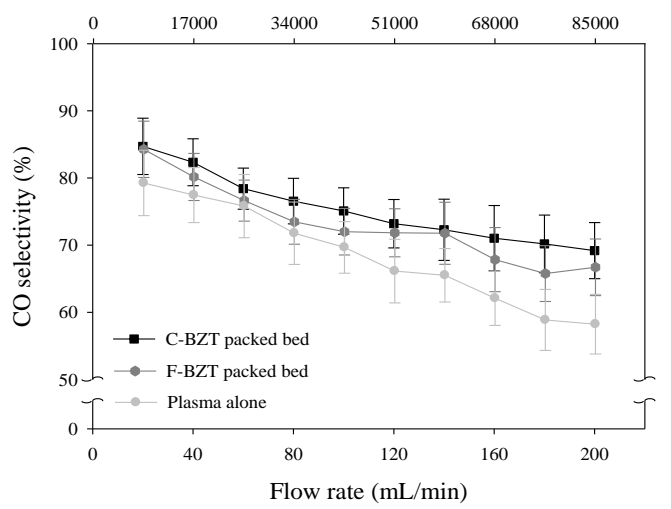

(f)

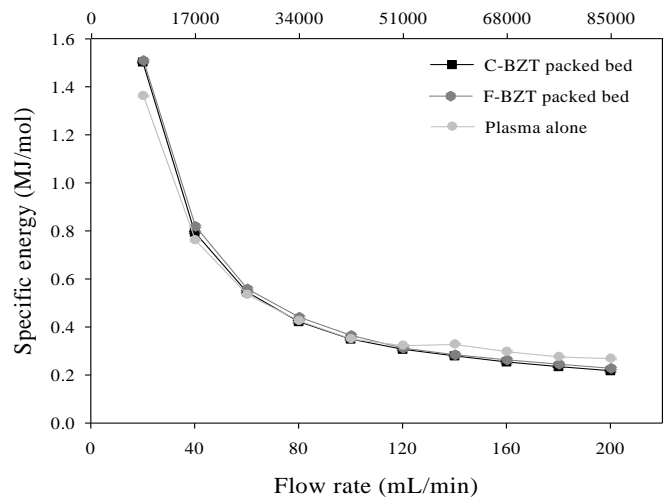

Fig. 5 Influence of ferroelectric size and GHSV on (a) $\mathrm{CH}_{4}$ conversion, (b) $\mathrm{CO}_{2}$ conversion, (c) $\mathrm{H}_{2}$ selectivity, (d) CO selectivity, (e) carbon balance and (f) specific energy. $\mathrm{CH}_{4} / \mathrm{CO}_{2}=1$, applied voltage $=13 \mathrm{kV}$, frequency $=20,000 \mathrm{~Hz}$ and discharge

$$
\text { gap }=5 \mathrm{~mm} .
$$


(a)

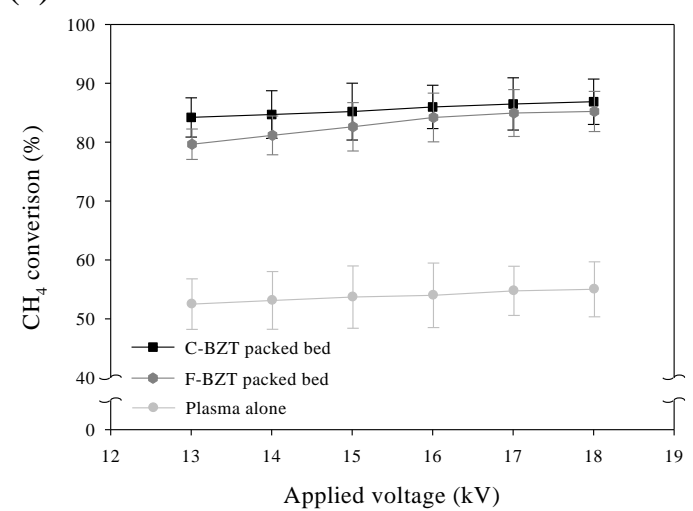

(c)

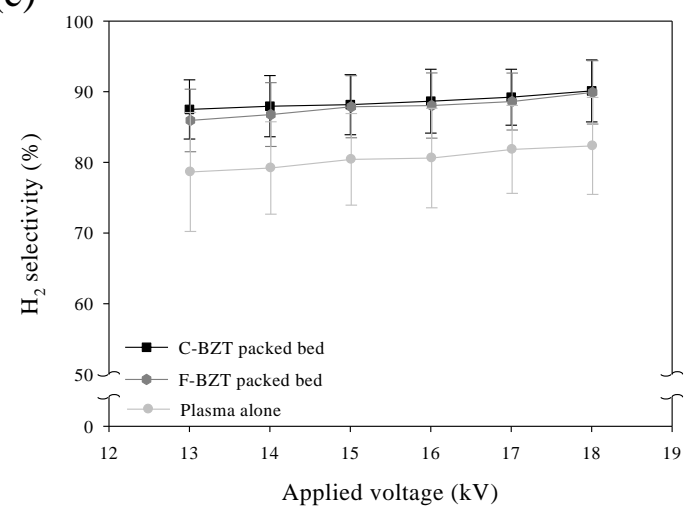

(e)

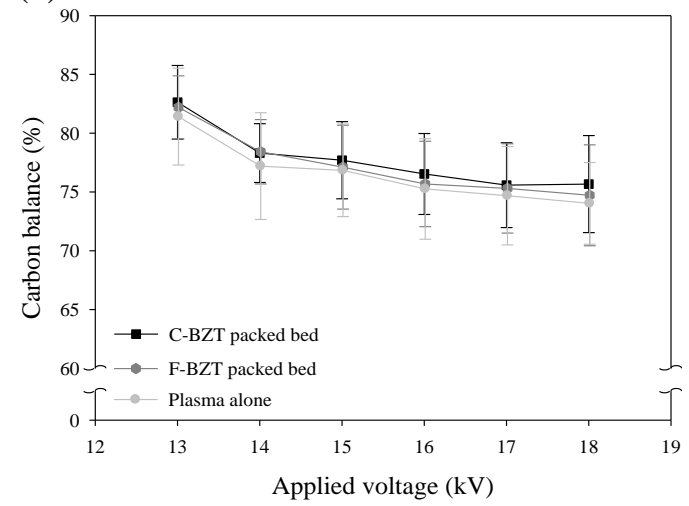

(b)

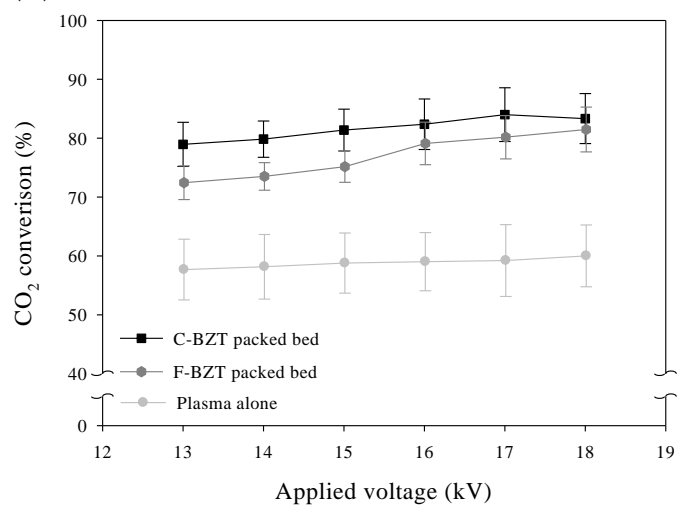

(d)

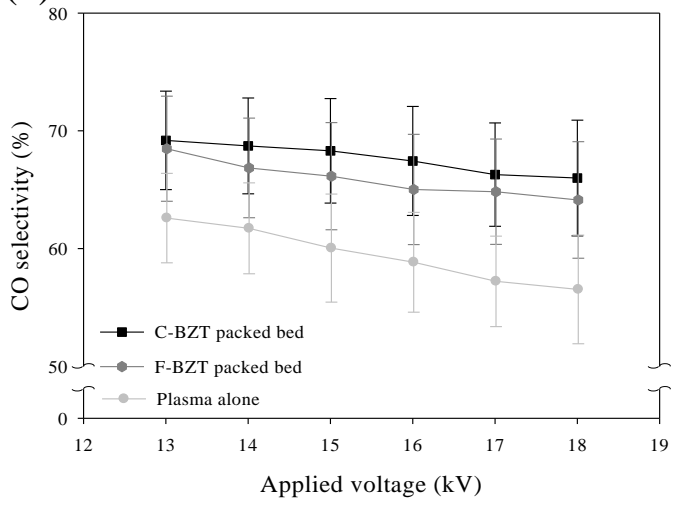

(f)

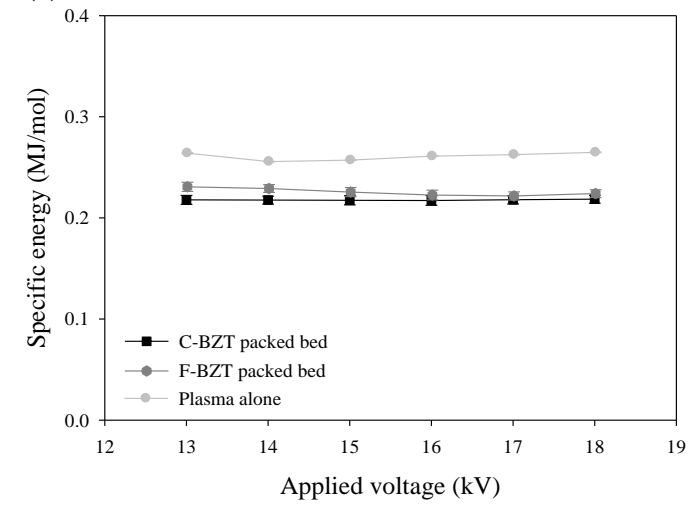

Fig. 6 Influence of ferroelectric size and applied voltage on (a) $\mathrm{CH}_{4}$ conversion, (b)

$\mathrm{CO}_{2}$ conversion, (c) $\mathrm{H}_{2}$ selectivity, (d) CO selectivity, (e) carbon balance and (f) specific energy. $\mathrm{CH}_{4} / \mathrm{CO}_{2}=1$, flow rate $=200 \mathrm{~mL} / \mathrm{min}, \mathrm{GHSV}=85,000 \mathrm{~h}^{-1}$, frequency $=20,000 \mathrm{~Hz}$ and discharge gap $=5 \mathrm{~mm}$. 


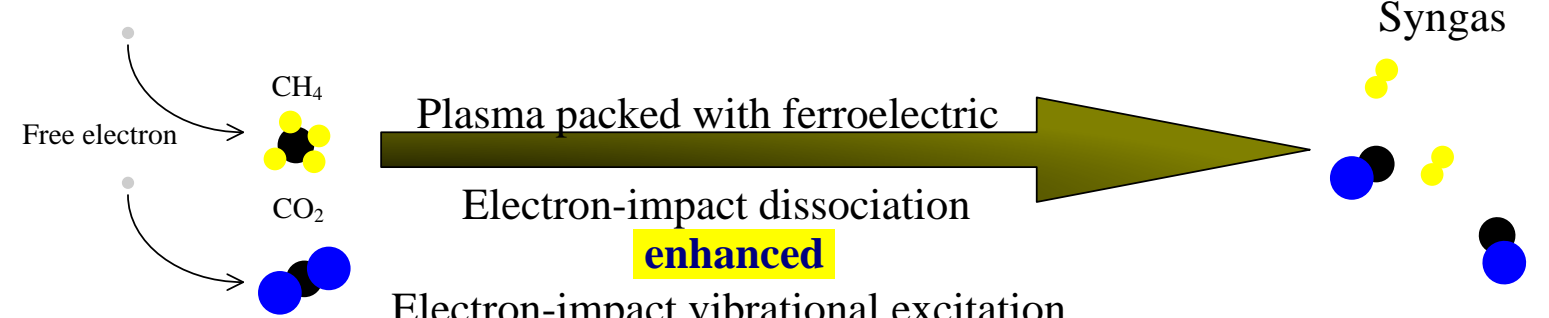

Electron-impact vibrational excitation
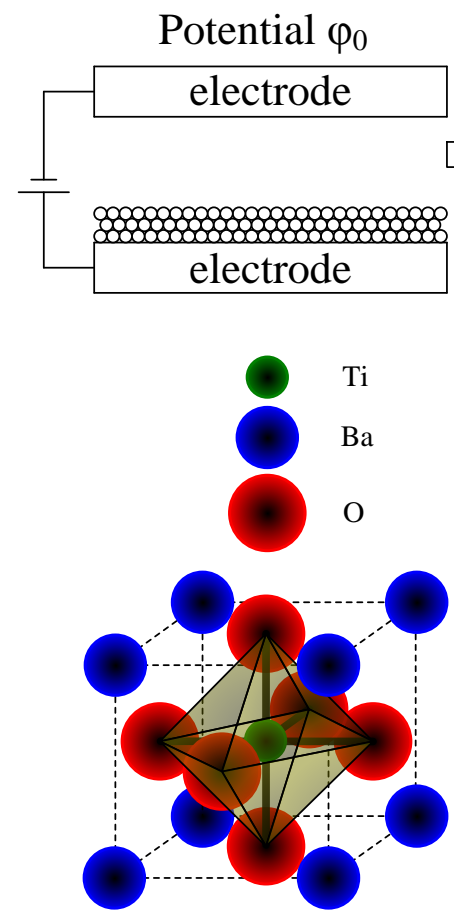

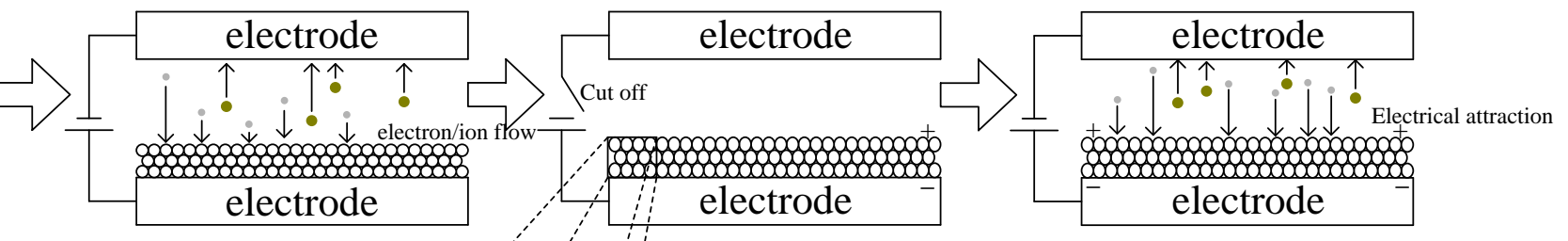

electron/ion flow
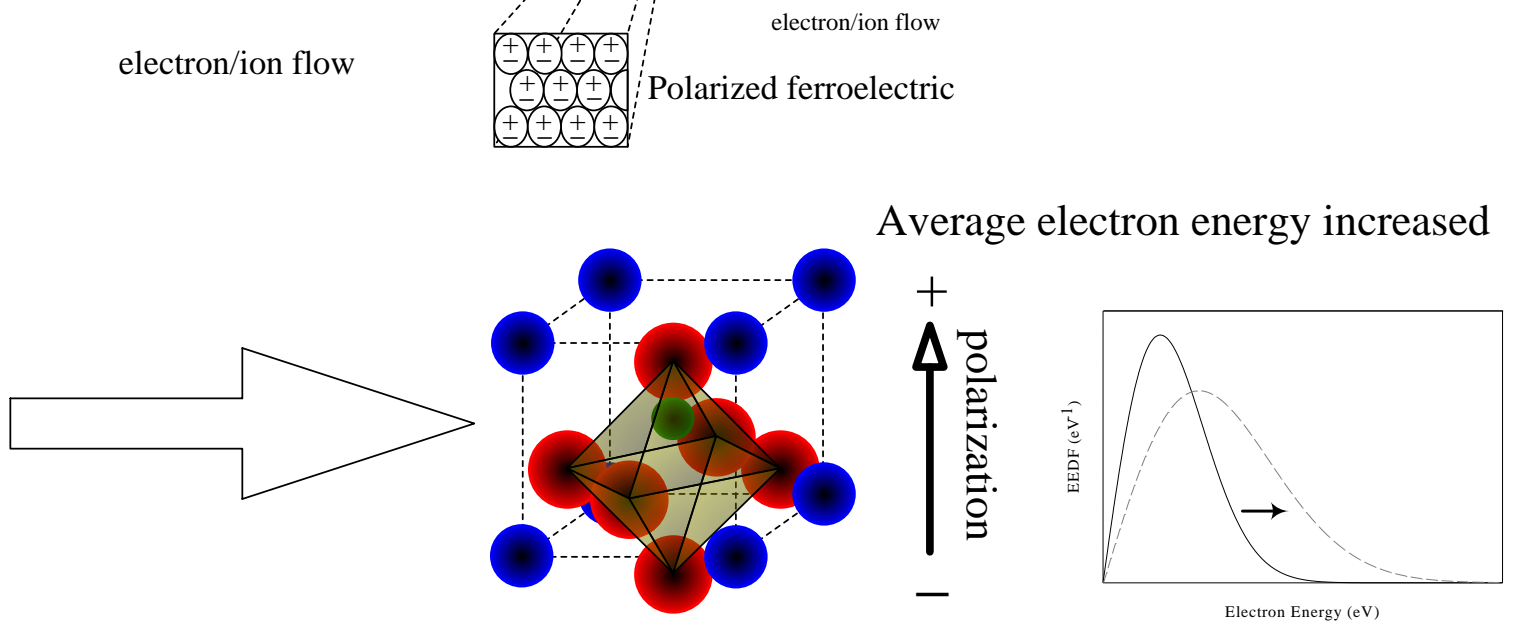

Fig. 7 Mechanism of ferroelectric polarization and its effect on reforming. 


\section{Table Captions}

Table 1 Crystal properties of BZT calculated from XRD results.

Table 2 BET and EDS results concerning BZT.

Table 3 Reforming performance under various operating conditions.

Table 4 Comparison of specific energies of plasma reactors for dry reforming of methane. 
Table 1 Crystal properties of BZT calculated from XRD results.

\begin{tabular}{lcccc}
\hline Ferroelectric & Space group & \multicolumn{3}{c}{ Lattice parameter (nm) } \\
\cline { 3 - 5 } & & $\mathrm{a}$ & $\mathrm{b}$ & $\mathrm{c}$ \\
\hline C-BZT & P4mm & 3.979 & 3.979 & 4.010 \\
C-BZT-P & P4mm & 3.983 & 3.983 & 4.018 \\
\hline
\end{tabular}


Table 2 BET and EDS results concerning BZT

\begin{tabular}{lcccccc}
\hline \multirow{2}{*}{ Ferroelectric } & Specific surface & Average pore & \multicolumn{4}{c}{ EDS (mol\%) } \\
\cline { 4 - 7 } & area $\left(\mathrm{m}^{2} / \mathrm{g}\right)$ & diameter $(\mathrm{nm})$ & $\mathrm{Ba}$ & $\mathrm{Zr}$ & $\mathrm{Ti}$ & $\mathrm{O}$ \\
\hline C-BZT & 7.77 & 5.3 & 19.6 & 2.4 & 19.7 & 58.3 \\
C-BZT-P & 16.65 & 4.8 & 20.1 & 1.7 & 19.8 & 58.6 \\
\hline
\end{tabular}


Table 3 Reforming performance under various operating conditions.

\begin{tabular}{|c|c|c|c|c|c|c|c|c|c|}
\hline \multirow[t]{2}{*}{ GHSV $\left(h^{-1}\right)$} & \multirow{2}{*}{$\begin{array}{l}\text { GHSV } \\
\left(\mathrm{h}^{-1}\right)\end{array}$} & \multirow{2}{*}{$\begin{array}{l}\text { Applied voltage } \\
(\mathrm{kV})\end{array}$} & \multirow[t]{2}{*}{ Ferroelectric } & \multicolumn{2}{|c|}{ Conversion (\%) } & \multicolumn{2}{|c|}{ Selectivity $(\%)$} & \multirow[t]{2}{*}{$\mathrm{CB}(\%)$} & \multirow[t]{2}{*}{ SE (MJ/mole } \\
\hline & & & & $\mathrm{CH}_{4}$ & $\mathrm{CO}_{2}$ & $\mathrm{H}_{2}$ & $\mathrm{CO}$ & & \\
\hline \multirow[t]{3}{*}{8,500} & 8,500 & 13 & w/o BZT & 83.3 & 80.5 & 65.0 & 80.5 & 86.8 & 1.36 \\
\hline & & & F-BZT & 98.2 & 91.3 & 70.9 & 84.3 & 92.5 & 1.51 \\
\hline & & & C-BZT & 98.6 & 92.5 & 70.9 & 84.7 & 92.9 & 1.57 \\
\hline \multirow[t]{3}{*}{85,000} & 85,000 & 13 & w/o BZT & 52.5 & 49.4 & 78.6 & 49.4 & 76.6 & 0.268 \\
\hline & & & F-BZT & 81.8 & 77.1 & 86.8 & 66.7 & 80.1 & 0.227 \\
\hline & & & C-BZT & 84.2 & 79.0 & 87.5 & 69.2 & 81.9 & 0.218 \\
\hline \multirow[t]{3}{*}{85,000} & 85,000 & 18 & w/o BZT & 55.0 & 60.0 & 82.3 & 56.5 & 74.0 & 0.265 \\
\hline & & & F-BZT & 85.2 & 81.5 & 89.9 & 64.1 & 74.7 & 0.224 \\
\hline & & & C-BZT & 86.9 & 83.3 & 90.1 & 66.0 & 75.7 & 0.218 \\
\hline
\end{tabular}


Table 4 Comparison of specific energies of plasma reactor for dry reforming of methane.

\begin{tabular}{|c|c|c|c|c|c|c|c|c|c|c|c|}
\hline \multirow[t]{2}{*}{ Plasma type } & \multirow[t]{2}{*}{ Packing material } & \multirow[t]{2}{*}{ Power $(W)$} & \multirow{2}{*}{$\begin{array}{l}Q \\
(\mathbf{m L} / \mathbf{m i n})\end{array}$} & \multirow{2}{*}{$\begin{array}{l}\text { GHSV } \\
\left(h^{-1}\right)\end{array}$} & \multirow{2}{*}{$\begin{array}{l}\text { Temperature } \\
\text { (K) }\end{array}$} & \multicolumn{2}{|c|}{ Conversion $(\%)$} & \multicolumn{2}{|c|}{ Selectivity (\%) } & \multirow{2}{*}{$\begin{array}{l}\mathrm{SE} \\
\text { (MJ/mole) }\end{array}$} & \multirow[t]{2}{*}{ Ref. } \\
\hline & & & & & & $\mathrm{CH}_{4}$ & $\mathrm{CO}_{2}$ & $\mathbf{H}_{2}$ & $\mathrm{CO}$ & & \\
\hline Microwave & - & 120 & 200 & $1.28 \times 10^{7}$ & N.P. & 72.0 & 68.0 & 52.4 & 74.0 & 1.38 & [43] \\
\hline Microwave & $\mathrm{AC}$ & N.P. & 42 & 320 & 1073 & 68.0 & 80.0 & N.P. & N.P. & N.P. & [44] \\
\hline Corona & - & 42 & 60 & N.P. & 420 & 69.0 & 58.0 & 73.0 & 93.8 & 1.39 & [45] \\
\hline Corona & $\mathrm{Ni} / \mathrm{Al}_{2} \mathrm{O}_{3}$ & 42 & 60 & N.P. & 420 & 68.8 & 55.0 & 70.4 & 94.3 & 1.44 & [45] \\
\hline DBD & $\mathrm{Ni} / \gamma-\mathrm{Al}_{2} \mathrm{O}_{3}$ & 50 & 50 & 263 & 503 & 38.0 & 21.0 & 28.0 & 45.0 & 3.07 & [46] \\
\hline DBD & $\mathrm{BaFe}_{0.5} \mathrm{Nb}_{0.5} \mathrm{O}_{3}$ & 23 & 40 & 22 & N.P. & 68.4 & 55.6 & 65.5 & 59.2 & 0.94 & [35] \\
\hline Gliding arc & - & 520.7 & 12,700 & N.P. & 723 & 41.8 & 37.1 & 38.4 & 55.0 & 0.52 & [47] \\
\hline Spark & - & 45 & 150 & 33,174 & 337 & 65.0 & 55.0 & 62.0 & 87.0 & 0.55 & [48] \\
\hline Spark & - & 26.6 & 200 & 85,000 & 873 & 53.1 & 58.1 & 79.2 & 61.7 & 0.27 & This study \\
\hline Spark & C-BZT & 39.3 & 200 & 85,000 & 873 & 86.0 & 82.4 & 88.7 & 67.4 & 0.22 & This study \\
\hline
\end{tabular}

N.P: not provided 